\title{
The Development and Tendency of Current Off-Shore Wind Power Plant All over the World
}

\author{
Zekun Wang $^{1,2}$ and Fuxi Zhang ${ }^{1, *}$ \\ ${ }^{1}$ Shanghai Ocean University, College of Science and Engineering, 201306 Shanghai, China \\ ${ }^{2}$ Auburn University, Department of Mechanical Engineering, 36849 Auburn, USA
}

\begin{abstract}
Based on the analysis of the new and accumulated offshore wind power installed capacity and wind farm and distribution in 2010-2019, this paper focuses on the prediction and comprehensive analysis of the scale of offshore wind power construction and approval in coastal provinces and cities by the end of 2019 and the projected grid-connected scale, current industrial status, and technical advantages and disadvantages in 2022-2025. The future technology development trend is forecasted, and the relevant policy recommendations are put forward.
\end{abstract}

\section{Overview of Marine Renewable Energy}

The first thought that comes to mind about marine energy is fossil fuels. Owing to massive exploitation along the coastline, great strides have been made so far that mining platforms can now go more in-depth and farther areas in the ocean for oils and other types of fuels. In the past 50 years, natural gas, such as methane, incredibly expands its pipeline deployments across the sea and land. Nevertheless, with the urgent need to effectively control global warming, enthusiasm for exploring for fossil energy has mainly been reduced to decrease the greenhouse gas emissions [1-5].

The renewable energy sources in the ocean comprise wind energy, wave energy, tidal energy, thermal energy, salinity gradients energy, biomass energy, etc., as demonstrated in Fig. 1. They are inexhaustible sources of energy and could be automatically regenerated in nature without human intervention $[6,7]$.

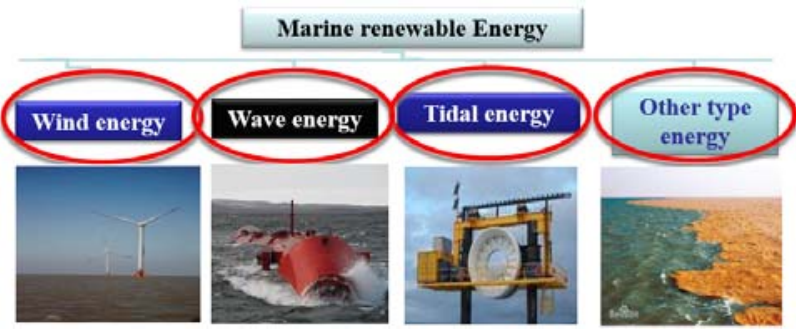

Figure 1. Various Marine Energy.

In recent decades, the offshore wind turbine is one of the most important types of all marine renewable energy sources. This "renewable" energy is widely distributed in any kind of offshore area with high density and good quality. The development of utilizing it requires relatively modest capital investment and the most advanced air turbine and marine equipment technologies.
The site selection requires more considerations due to the noise from the running wind turbine, and the right site choice could suppress adverse conditions. Offshore wind farms have been used in many areas all over the world. However, there are also environmental objectives, which have prompted engineers to design new optimization technologies.

\section{Current International Development and Trend of Offshore Wind Power}

\subsection{Foreign Offshore Wind Power Installed Capacity and Wind Farm}

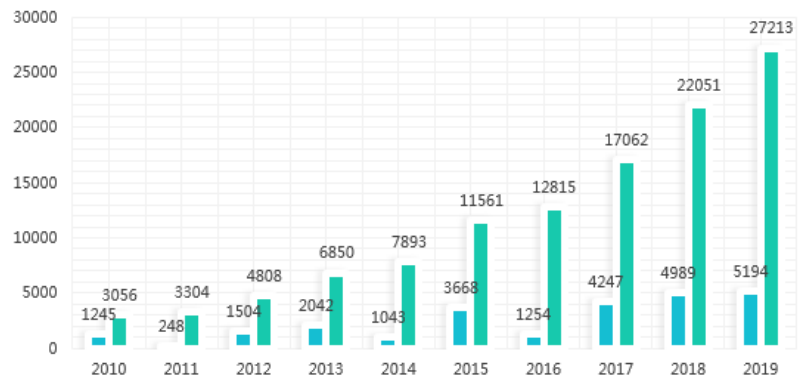

Figure 2. 2010-2019 Global Wind Power Instalments (Units:MW)

In 2018 , global wind power capacity grew $9.6 \%$ to 591 GW. In 2019, a total of 16 new offshore wind farms had been built and put into operation, with a total installed capacity of $5.2 \mathrm{GW}$. The UK remains the leader in terms of the installed capacity of offshore wind farms that have been shipped around the world. In 2019, the cumulative installed capacity of offshore wind power in the UK reached $9.7 \mathrm{MW}$, followed by Germany, with a cumulative installed capacity of $7.5 \mathrm{GW}$, of which China

\footnotetext{
* Corresponding author: author@e-mail.org
} 
had 13 offshore wind projects under construction, accounting for $56.5 \%$ of the world. China is the thirdlargest market in the world for offshore wind power, with a cumulative installed capacity of $4.9 \mathrm{GW}$. According to a recent report by industry consultancy Wood Mackenzie, global investment in offshore wind power industry will exceed $\$ 200$ billion from 2020 to 2025. It is expected that investment in the global offshore wind power industry will remain relatively stable from 2020 to 2022 . From 2023 to 2025, the industrial investment will grow exponentially, and offshore wind projects will increase by $63 \%$ by 2025 . Wind power is expected to provide 4 million kilowatts of generating capacity by 2028 , and a dozen-fold increase from the current level. Japan plans to install more than $10 \mathrm{GW}$ offshore wind power by 2030 [8].

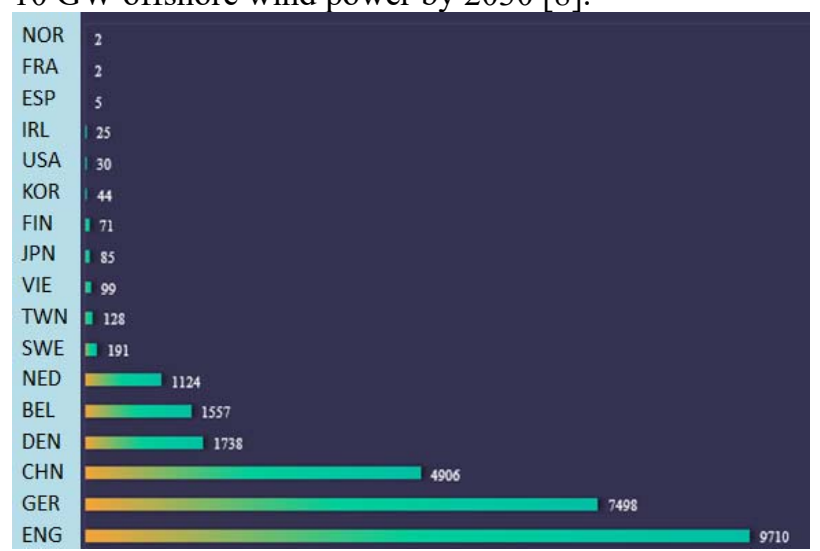

Figure 3. 2019 Wind Power Instalments of Nations (Units: MW)

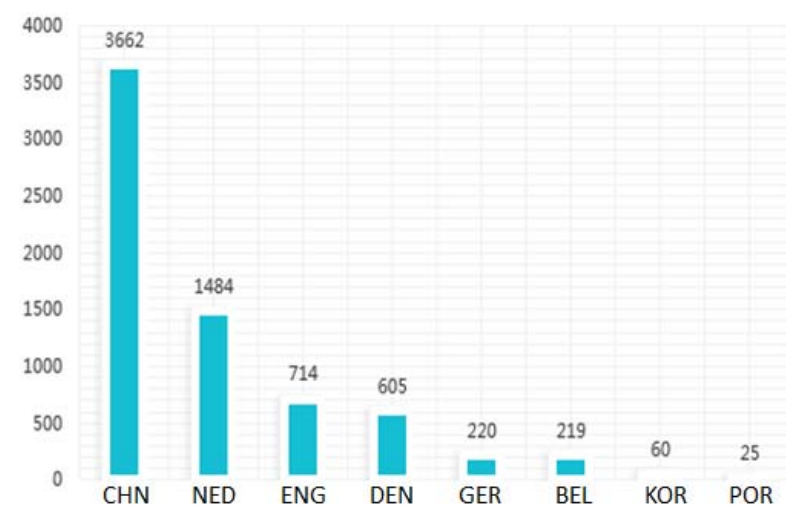

Figure 4. 2019 Wind Power Capacity of Nations (Units: MW)

Offshore wind projects under construction, led by the Borssele 3-4 project in the Netherlands, will have an installed capacity of 732MW, followed by East Anglia One in the UK, Kriegers Flak in Denmark and Jiangnan Peng Island in Zhongguang Nuclear, with an installed capacity of more than $400 \mathrm{MW}$. Offshore wind projects under construction, led by the Borssele 3-4 project in the Netherlands, will have an installed capacity of $732 \mathrm{MW}$, followed by East Anglia One in the UK, Kriegers Flak in Denmark and Jiangnan Peng Island in Zhongguang Nuclear, with an installed capacity of more than 400MW [9].

\section{Current Situation and Trend of Offshore Wind Power Generation in China}

\subsection{Scale of Offshore Wind in China under Construction and Approval}

In December 2019, China's offshore furthest (offshore straight line distance of 42 kilometers), the construction of the most difficult offshore wind power project of 30 million kilowatts, invested by The State Energy Group Guohua, was successfully installed in the waters off the coast of Dongtai, Jiangsu Province, and was connected to the grid.

China's coastline is 18,000 kilometers long, the available sea area of more than 3 million square kilometers, offshore wind energy resources are rich, great potential. According to the results of the first wind energy resource evaluation of the China Meteorological Administration, the height of $50 \mathrm{~m}$ above sea level in the offshore area within the $5-25 \mathrm{~m}$ iso-deep line of China's coast can be installed at an elevation of 200,000 MW, and offshore wind energy resources are not only large reserves, but also suitable for large-scale centralized development. Liaoning, Hebei, Shandong, Zhejiang, Fujian, Guangdong, and other provinces have the advantages of building large-scale offshore wind farms. China's coastal wind power generation has entered the stage of a large-scale application, and the Offshore wind farm of Donghai Bridge has been successfully connected to the grid for power generation, which has the conditions for commercial trial development [10].

In 2014-2019, China's cumulative wind power installed continued to grow, as of the end of 2019, the country's cumulative wind power installed 210 million kilowatts, up 14.0\% YoY, in 2019, offshore wind power installed 1.98 million kilowatts, offshore wind power installed 5.93 million kilowatts. According to China's "13th Five-Year Plan" for renewable energy development, by 2020, China's offshore wind power construction started 10 million kilowatts, to ensure the completion of 5 million kilowatts, the market prospects are broad.

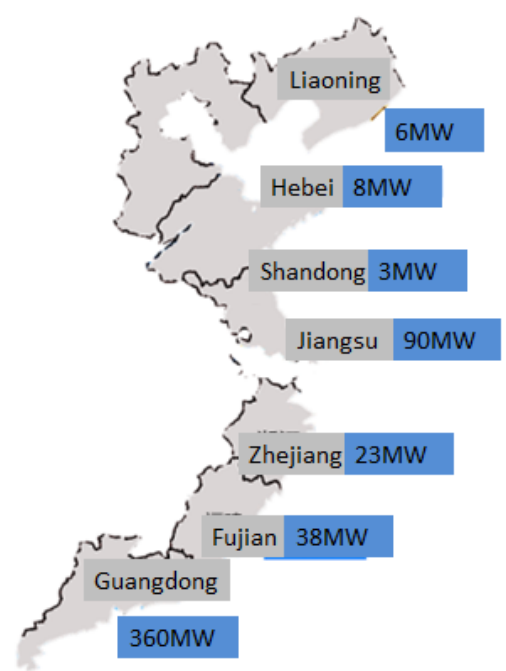

Figure 5. Nationwide Wind Power Approvals (Units: 10MW) 


\subsection{Current Situation, Technical Advantages and Disadvantages of China's Offshore Wind Power Industry}

The H210-10MW (MW) offshore wind turbine, independently designed and developed by China National Shipping Group, can increase the power generation capacity of the unit by $98 \%$ under the same wind resource conditions with an average annual wind speed of $10 \mathrm{~m} / \mathrm{s}$ (standard air density). The offshore wind turbine has filled the gap of China's super-large offshore wind turbine through design certification [11].

China's first offshore wind farm national standard "offshore wind farm design standards" (GB/T 513082019) was officially released, in October 2019.

With the trend of the large-scale fan, large fan blades are also regarded as one of the symbols of the technical strength of enterprises. At present, the direction of blade research and development of wind turbine steaming is basically positioned in light, high strength, large-scale, modular. Oriental Electric Wind Power Co. , Ltd. 10 MW power class B900A bladein in Tianjin Blade Company, the blade length of 90 meters, is currently the largest power class, the longest length of wind blades.

It is expected to be completed and put into operation in 2020 more than 10 large-scale offshore blade production lines. After all production, Mingyang Intelligent will have an annual output of more than 700 sets of largescale offshore blade production capacity.

Shanghai Electric Wind Power Guangdong Offshore Intelligent Manufacturing Project, located in Guangdong Shantou Lujiang District, Guanggao Logistics Park. Plans to produce 4 to $10 \mathrm{MW}$ offshore wind power mainframe equipment, the project introduced Siemens 4.0 MW, 6.0 MW, 7.0 MW offshore wind turbine, these units are currently the world's most advanced technology mature, the world's best large-scale operation performance offshore wind turbines, forming an annual output of 200 sets of wind power equipment production capacity. It represents the highest level of offshore wind turbine production and manufacturing in Asia.

In September 2019, China's independent research and development, single-machine capacity in the AsiaPacific region, the world's second-largest 10MW, 8MW offshore wind turbine offline, marking China has mastered the key core technology of offshore wind power large-capacity unit research and development, into the world's advanced ranks of offshore wind power development.

China and Europe offshore wind technology gap is gradually narrowing, $5 \mathrm{MW}$ wind turbine has become China's offshore wind power project tender mainstream models, $7 \mathrm{MW}$ wind turbine has been commercialized operation, $10 \mathrm{MW}$ wind turbine is accelerating the process of localization, some enterprises have begun to study $15 \mathrm{MW}$ wind turbine. The gap with foreign offshore wind power technology gradually narrowed and went abroad, in response to the "Belt and Road" initiative, offshore wind power project results exported to South Africa, Sweden, Spain, and other countries; the project team has successfully won contracts for projects such as the Swedish K-M project, the METROWIND project in South Africa and the BTE project in South Africa, and has signed wind power development agreements with Brazil, Ireland, and other countries. China's offshore wind power technology is gradually maturing, is entering a large-scale commercial development stage.

There are three disadvantages to the development of offshore wind power in China: strong typhoons, soft foundations, and short construction window periods. In particular, China's offshore wind resources and seabed conditions do not have an advantage, and technology drives offshore wind power to the deepwater area. It is more necessary to plan ahead in the field of deep-water wind power technology in the distant sea, early reserve. Whether we can succeed at the end to the sea requires a variety of innovative technologies and demonstration projects to drive. Therefore, China's offshore wind power needs to move far-reaching to the sea.

\section{Development Trend of Offshore Wind Power in China}

\subsection{Formalization}

China's 2020 offshore wind development target has been increased from about $5 \mathrm{GW}$ grid-connected capacity and $10 \mathrm{GW}$ to about $9 \mathrm{GW}$ grid-connected capacity and 30 GW in construction. China's wind motor oetype equipment manufacturer's delivery capacity of about 5.8 GW by 2020 , plus $5.25 \mathrm{GW}$ in 2021 , with a total installed capacity of $11.05 \mathrm{GW}$ by the end of 2020 or early 2021, Will become the world's largest installed offshore wind power country [12].

In Guangdong Province, for example, the amount of offshore wind power grid in Guangdong Province is only about 180,000 kilowatts, or $0.3 \%$ of the total planned amount. According to the Guangdong Provincial Development and Reform Commission officially issued the Guangdong Provincial Maritime Development Plan (2017-2030) (revised), the province's planned total installed capacity of offshore wind power is 66.85 million kilowatts. Among them, the offshore shallow water area (within 35 meters of water depth) installed capacity of 9.85 million kilowatts, offshore deepwater area (35-50 meters deep water depth), completed 57 million kilowatts.

According to authoritative forecasts, 10.8 million installed offshore wind projects in China could be connected to the grid between 2019 and 2021. By 2022, the size of the new grid will fall by a third. However, in view of China's huge offshore wind development potential and stability policy, China's offshore wind power installed capacity will reach $40.4 \mathrm{GW}$ in 2028. During the 13th Five-Year Plan period, China's offshore wind power grid-connected scale is 7.9 million kilowatts, with an expected grid-connected size of 4 million kilowatts in 2021 and 14 million to 15 million kilowatts in 2022-2025. From 2023 to 2028, the average annual installed capacity will exceed 4 million kilowatts. China's offshore wind power "13th Five-Year Plan" will surpass Germany as the world's second-largest offshore 
wind market. During the 14th Five-Year Plan period, China's offshore wind power is expected to be installed about 18 million kilowatts, and the cumulative installed capacity will reach 25 million kilowatts in 2025, surpassing the United Kingdom as the world's largest offshore wind market. From 2031 to 2050, China will realize the all-round development of wind power on land and in the near and far seas.

\begin{tabular}{|c|c|c|c|}
\hline Area & Year & Before (GW) & After (GW) \\
\hline Jiangsu & 2012 & 12.15 & 14.46 \\
\hline Zhejiang & 2016 & 6.47 & \\
\hline Fujian & 2017 & 10.6 & 13.3 \\
\hline Guangdong & 2018 & 10.71 & 66.85 \\
\hline Hainan & 2014 & 3.95 & \\
\hline Shandong & 2012 & 12.74 & \\
\hline Shanghai & 2011 & 5.95 & 6.15 \\
\hline Hebei & 2012 & 5.8 & \\
\hline Liaoning & 2013 & 2.2 & 74.93 \\
\hline Total & & 70.58 & 74.93 \\
\hline
\end{tabular}

Figure 6. Nationwide Wind Power Plans

\subsection{Floating Wind Power}

The design limitations of conventional offshore wind farms mean that they must be built in relatively shallow waters and close to land, with a fixed base cost of more than $100 \mathrm{~m}$ at depths, from shallow to deep. Compared to fixed, floating platforms allow wind turbines to be deployed almost anywhere in the sea, maximizing the potential of offshore wind energy, not only opening up exploitable sea areas, but also having shorter development cycles and being more environmentally friendly, and are the main technologies for far-reaching offshore wind development in the future. According to statistics, there are currently nearly 30 million $\mathrm{kW}$ offshore wind power in operation worldwide, of which more than two-thirds in Europe. Denmark, the Netherlands, and the Uk are the countries with the largest number of wind turbines, not only with port infrastructure and technology, but also invaluable land space, which has contributed in part to innovation in floating offshore wind technology. To date, the only one using multiple (5 6MW fans) floating wind power is the Hywind Scotland offshore wind project (30MW) developed by Equinor, the world's first commercial offshore floating wind project.

At the end of 2019, WindEurope, the European wind energy association, proposed that the European offshore wind installation target should reach $450 \mathrm{GW}$ by 2050 , of which 100 to $150 \mathrm{GW}$ will be provided by floating wind farms. Currently, the largest floating wind farm under construction in the world is the Hywind Tampen project in Norway developed by Equinor, with an installed capacity of $88 \mathrm{MW}$, which is expected to be launched in 2022. Instead of connecting to the onshore grid, the project supplies power to nearby oil exploration platforms and eliminates the cost of sending cables. Since floating wind farms are generally far off offshore, the laying of cables will be a significant investment. According to the International Energy Agency, wind farms with water depths of less than $60 \mathrm{~m}$ and less than $60 \mathrm{~km}$ offshore worldwide have an annual installed capacity of $36,000 \mathrm{tW}$, while global electricity demand is
23,000 tW. Offshore wind farms are moving deeper into the sea, and offshore floating wind power generation will reach 11 times the world's electricity demand by 2040 .

\section{3. "Intelligence" Becoming a New Trend in Wind Power Development}

In response to the development trend of decentralized and offshore wind power, a number of companies have been carrying out low wind speed regional onshore and offshore large MW intelligent unit technology research, with information innovation design and development system, is committed to improving the intelligent level of wind turbines, improve the information technology content of fans.

Smart blades can know the shape of the blades at any point, at any azimuth, and then know the entire distance when the wind wheel sweeps through the cylinder, depending on the deformation. The root of the intelligent blade can adjust the distance to the pole based on the force of the leaf root, but also according to the image processing technology to restore its original position with a special coating on the blade. This can not only monitor the health of the blades in real time, but also avoid the problem blades continue to operate caused by more damage.

Fan intelligent technology is also reflected in the tower, through high-precision inertial guidance technology can accurately reduce the tower displacement, through dynamic static displacement can know the foundation of the tower subsidence, the amount of deformation at any time, can also be based on the tower can understand the force situation, before the problem stoliain to take appropriate remedial measures.

In the construction of offshore wind power, the turbine arrangement will have an important impact on the whole life cycle of the project. Smart wind field can make comprehensive use of "Internet plus", big data, cloud platform, and other technologies. Based on the centralized data platform, it carries out comprehensive big data analysis work, and then find defects of the fan to prevent the failure with active control, implemental operation, and maintenance [13].

\section{Relevant Policy Research and Recommendations}

\subsection{Offshore Wind Power "One Size Fits All" Tariff Model Needs to Be Changed}

On May 21, 2019, the official website of the National Development and Reform Commission (NDRC) issued the Notice on Improving the Tariff Policy for Wind Power Feed-in Tariffs for The Reform price (2019 No. 882 ), which clarified the tariff policy for new onshore wind and offshore wind power projects for 2019 and 2020, and also made it clear that the new approved offshore wind power in 2020 will no longer be included in the scope of state subsidies. In 2021, the newly approved onshore wind power project will fully realize 
the affordable Internet access, and the feed-in tariff determined by competitive means shall not be higher than the guide price of $0.75 \mathrm{Yuan} / \mathrm{kWh}$. In the next 5 years, the cost of offshore wind power in China is expected to drop by more than $40 \%$, and by 2025 , we will basically achieve parity without subsidies. It is estimated that the subsidy funds required for the installation of new grid-connected installations from 2022 to 2025 will be 1.5 billion yuan, 1.2 billion yuan, 600 million yuan, and 300 million yuan, respectively. When online, the local finance of coastal provinces needs to formulate a policy of electricity price subsidy.

The main ways of reducing the cost of offshore wind power include centralized scale development, improved performance of wind turbines, and technological innovation and capacity enhancement in survey, design and construction. Offshore wind power prices cannot adopt a one-size-fits-all model.

\subsection{Improving the Offshore Wind Power Supply Chain}

In order to catch the net by the end of 2021, domestic offshore wind power developers are starting a number of offshore wind projects on a large scale. But only $20 \%$ of offshore wind projects approved will be connected to the grid by the end of 2021, thanks to bottlenecks in the domestic supply chain, according to the latest Wood Mackenzie report. In order to obtain high fixed feed-in tariff, in the past year, the provinces and cities centrally approved several batches of offshore wind power projects, a cumulative total of about 50 million kilowatts. While this has long-term confidence in companies that continue to invest in China's offshore wind industry, it has put enormous pressure on short-term supply for companies in the relevant supply chain. Developers will face greater profit pressure, only the supply chain to accelerate maturity, improve can reduce investment costs. These investments will drive hundreds of billions of yuan of investment each year, create tens of thousands of jobs and, more importantly, effectively support the healthy and sustainable development of the built and planned offshore wind power equipment manufacturing base, and the healthy and sustainable development of supporting industries such as the Port of Victoria.

\subsection{Research and Development of Offshore Wind Power Operation and Maintenance Equipment}

Wind power installation vessels are the main obstacle spree for some domestic offshore wind projects that cannot be completed and put into operation on schedule by 2022 . According to China's ship inspection statistics, as of the beginning of April 2019, the domestic put into use a total of 22 wind power installation vessels, 7 are under construction. Although it has become the largest wind installation ship market outside Europe, it is still unable to meet the short-term "swarm" construction demand for domestic projects.

\subsection{Digital and Intelligent}

Compared with hydropower, thermal power and onshore wind power, offshore wind power development is more difficult. On the one hand, the sea wind and waves flow conditions are very bad, and the marine geological conditions are complex, fan equipment year-round suffering from high salt spray, on the other hand, with the continuous development of offshore wind power to the far-reaching sea, its reach is getting lower and lower, equipment once malfunctioning, maintenance is quite difficult.

In the whole machine anti-corrosion, equipment reliability, fan advanced and economic aspects, the use of a "redundant" design concept can make the digital intelligent take a corner overtaking [14].

\section{Conclusions}

China has abundant offshore wind power resources. In recent years, the rapid development of offshore wind power technologies has reached the advanced international level. But overall, China's offshore wind power development is still in the initial stage. From the survey and design, construction management, operation and maintenance, technological innovation, industrial financing, and other aspects are not yet mature; the need for the relevant supporting industrial chain promotes the comprehensive integration and development of the offshore wind power industry chain. There is no doubt that in the gradual development of offshore wind power projects, offshore wind power design, construction, etc. will accumulate rich experience, phase development will be increasingly perfect.

Acknowledgements: The authors would like to express their gratitude for the support of Shanghai Engineering Research Center of Marine Renewable Energy ( Grant No. 19DZ2254800).

\section{References}

1. Andresen, Tino. Molten Aluminum Lakes Offer Power Storage for German Wind Farms , Bloomberg, 27 October 2014.

2. Buczynski, Beth (23 August 2012). Power To Gas Technology Turns Excess Wind Energy Into Natural Gas. Revmodo.com. Archived from the original on 5 October 2012.

3. Shahan, Zachary (27 July 2012). Wind Turbine Net Capacity Factor - 50\% the New Normal?. Cleantechnica.com. Retrieved 11 January 2013.

4. WindpoweringAmerica.gov Archived 2 May 2013 at the Wayback Machine., 46. U.S. Department of Energy; Energy Efficiency and Renewable Energy "20\% Wind Energy by 2030"

5. Simon Chapman. Summary of main conclusions reached in 25 reviews of the research literature on 
wind farms and health, Sydney University School of Public Health, April 2015

6. European Commission (2014) Directive 2014/89/EU of the European Parliament and of the Council: Establishing a Framework for Maritime Spatial Planning. Official Journal of the European Union, 135-145.

7. Rawn,B.G.;Vanereijden,M.A.AnalysisofNorthSeaOf fshoreWindPowerVariability.Resources2014, 3, 454-470.

8. M. Y. Abdellah, M. S. Alsoufi, M. K. Hassan, H. A. Ghulman, and A. F. Mohamed, "Extended finite element numerical analysis of scale effect in notched glass fiber reinforced epoxy composite," Archive of Mechanical Engineering, vol. 62, pp. 217-236, 2015.

9. DONG Xiao-feng,LIAN Ji-jian,WANG Hai-jun. Study on Vibration Source Features of Offshore Wind Power Structure under the Operational Conditions[J]. JOURNAL OF VIBRATION AND SHOCK, 2017, 36(17): 21-28.

10. FU Yang,ZHENGZichen,SHI Shuai, et al. Offshore Wind Power Forecasting Considering Meteorological Similarity and NWP Correction[J]. POWER SYSTEM TECHNOLOGY, 2019, 43(4): 1253-1259.

11. Kühn, B., Krieglstein, T.: BedarfsgerechteWerkstoffwahlzurVermeidung von SprödbrüchenfürGründungsbauteile von OffshoreWindkraftanlagenaus Stahl gemäß DIN EN 1993-110, Abschlussbericht, Technische Hochschule Mittelhessen, 2016.

12. HuimingZhang, YuZheng, DequnZhou, XingleLong.Selection of key technology policies for Chinese offshore wind power: A perspective on patent maps,Marine Policy Volume 93, July 2018, Pages 47-53

13. Felix Optehostert,Daniela Müller,Philipp Jussen.Dispositioning Strategies of Maintenance Tasks in Offshore Wind Farms, from book Advances in Production Management Systems. The Path to Intelligent, Collaborative and Sustainable Manufacturing (Proceedings of: IFIP WG 5.7 International Conference, APMS 2017, Hamburg, Germany, September 3-7, 2017, Part I and II) pp.101-108

14. Linus Hammar, Diana Perry, Martin Gullström.Offshore Wind Power for Marine Conservation,OJMS, Vol.6 No.1, January 2016,PP. 66-78 